\title{
State-Dependent Effects of Transcranial Oscillatory Currents on the Motor System: What You Think Matters
}

\author{
Matteo Feurra, ${ }^{1}$ Patrizio Pasqualetti, ${ }^{2,3}$ Giovanni Bianco, ${ }^{1}$ Emiliano Santarnecchi, ${ }^{1}$ Alessandro Rossi, ${ }^{1}$ \\ and Simone Rossi ${ }^{1}$ \\ ${ }^{1}$ Dipartimento di Scienze Neurologiche e Neurosensoriali, Sezione di Neurologia e Neurofisiologia Clinica, Azienda Ospedaliera-Universitaria Senese, \\ Policlinico Le Scotte, I-53100, Siena, Italy, ${ }^{2}$ Servizio di Statistica Medica e Tecnologie di Informazione, Associazione Fatebenefratelli per la Ricerca \\ Biomedica e Salute, Centro San Benedetto Menni-Fatebenefratelli, I-00186, Roma, Italy, and ${ }^{3}$ Epidemiologia e Biostatistica, Casa di Cura "San Raffaele- \\ Cassino", Tosinvest, I-03043, Cassino, Italy
}

Imperceptible transcranial alternating current stimulation (tACS) changes the endogenous cortical oscillatory activity in a frequencyspecific manner. In the human motor system, tACS coincident with the idling beta rhythm of the quiescent motor cortex increased the corticospinal output. We reasoned that changing the initial state of the brain (i.e., from quiescence to a motor imagery task that desynchronizes the local beta rhythm) might also change the susceptibility of the corticospinal system to resonance effects induced by betatACS. We tested this hypothesis by delivering tACS at different frequencies (theta, alpha, beta, and gamma) on the primary motor cortex at rest and during motor imagery. Motor-evoked potentials (MEPs) were obtained by transcranial magnetic stimulation (TMS) on the primary motor cortex with an online-navigated TMS-tACS setting. During motor imagery, the increase of corticospinal excitability was maximal with theta-tACS, likely reflecting a reinforcement of working memory processes required to mentally process and "execute" the cognitive task. As expected, the maximal MEPs increase with subjects at rest was instead obtained with beta-tACS, substantiating previous evidence. This dissociation provides new evidence of state and frequency dependency of tACS effects on the motor system and helps discern the functional role of different oscillatory frequencies of this brain region. These findings may be relevant for rehabilitative neuromodulatory interventions.

\section{Introduction}

In the absence of sensory information processing or motor output, the prevailing oscillating "natural frequency" of sensorimotor areas (Rosanova et al., 2009) is an idling $\beta$ activity peaking at $\sim 20 \mathrm{~Hz}$ (Niedermeyer, 1999). Task-related changes of spatiospectral properties of topographically organized oscillatory brain activity occur during dynamic changes of motor outputs (Omlor et al., 2011), reflecting different cognitive states and functions (Thut and Miniussi, 2009).

In animal models, weak sinusoidal transcranial alternating current stimulation (tACS) entrains the discharge frequency of widespread cortical neurons (Ozen et al., 2010). This experimental evidence was used to postulate a similar mechanism to explain frequency-specific effects of imperceptible tACS onto the endog-

\footnotetext{
Received April 3, 2013; revised Sept. 17, 2013; accepted Sept. 20, 2013.

Author contributions: M.F. and S.R. designed research; M.F., G.B., and E.S. performed research; P.P. analyzed data; M.F., P.P., A.R., and S.R. wrote the paper.

The study has been supported by the Young Researchers Project, Ministero della Salute Project GR-20091591481, and partly by the European Commission with Collaborative Project 248587, THE Hand Embodied, within the FP7-ICT-2009-4-2-1 program Cognitive Systems and Robotics. We are grateful to Dr. Giulia Galli for English style revision.

The authors declare no competing financial interests.

Correspondence should be addressed to Dr. Simone Rossi, Dipartimento di Scienze Neurologiche e Neurosensoriali, Sezione Neurologia e Neurofisiologia Clinica, Laboratorio di Investigazione Cerebrale e Neuromodulazione, Azienda Ospedaliera Universitaria Senese, Policlinico Le Scotte, Viale Bracci, I-53100, Siena, Italy. E-mail: rossisimo@unisi.it.

DOI:10.1523/JNEUROSCI.1414-13.2013

Copyright $\odot 2013$ the authors $\quad 0270-6474 / 13 / 3317483-07 \$ 15.00 / 0$
}

enous cortical oscillatory activity in humans (Zaehle et al., 2010; Polanía et al., 2012). tACS may exert behavioral consequences on perceptual (Kanai et al., 2008, 2010; Feurra et al., 2011c), motor (Pogosyan et al., 2009; Brittain et al., 2013), and cognitive (Marshall et al., 2006; Feurra et al., 2012; Sela et al., 2012; Santarnecchi et al., 2013) tasks. In the motor system, tACS coincident with the idling $\beta$ rhythm of the resting motor cortex increased the corticospinal output (Feurra et al., 2011b). Moreover, tACS may slow down (at the $\beta$ range) or speed up (at high $\gamma$ range) voluntary movements, thus suggesting that brain oscillations are causal, rather than epiphenomenal, to motor behavior (Joundi et al., 2012).

We aimed to investigate whether modulatory tACS effects extend to motor imagery (MI), which desynchronizes neural networks activity in sensorimotor regions (Niedermeyer, 1999; McFarland et al., 2000) and increases the excitability of the corticospinal system toward muscles engaged in the motor plan (Rossini et al., 1999). We reasoned that, if MI desynchronizes the rolandic $\beta$ rhythm, neural generators of such oscillations might then become less susceptible to effects of $\beta$-tACS, thereby reducing their degree of corticospinal excitability.

$\mathrm{MI}$ is a demanding cognitive operation that involves the conscious rehearsal of egocentric actions without overt motor output (Jeannerod, 1995). Similar to movement execution, MI engages a wide frontoparietal network (McFarland et al., 2000; Munzert et al., 2009). In addition, MI involves working memory (WM) processes needed to retrieve a motor scheme and maintain it for 
upcoming tasks, throughout a continuous allocation of attentional resources (Decety and Grezes, 1999). Visuospatial WM is associated with slow oscillations in the $5 \mathrm{~Hz}$ theta band (Düzel et al., 2010; Sauseng et al., 2010), which also plays a key role during motor planning, learning (Kaplan et al., 2012), and movementtarget selection (Rawle et al., 2012). Therefore, during MI, $\theta$-tACS, rather than $\beta$-tACS, might be more effective to induce resonance effects on the motor cortex.

The present study aimed to investigate the state and frequency dependence of tACS effects on the motor cortex. We randomly delivered electrical currents in the $\theta, \alpha, \beta$, and $\gamma$ bands while subjects were quiescent or engaged in MI. Control conditions were no-tACS and tACS applied on the parietal cortex (PC). The size of motor responses recorded during navigated transcranial magnetic stimulation (TMS) of the motor cortex (Feurra et al., 2011b) was used as a marker of tACS-induced corticospinal excitability.

\section{Materials and Methods}

Participants. Eighteen fully healthy right-handed volunteers ( 8 females, 10 males; mean age, $32.2 \pm 7$ years), naive to the purpose of the experiment, were included in the study after being screened for suitability to TMS (Rossi et al., 2009). They reported no history of implanted metal devices or neurological or psychiatric disease. They also stated that they did not take drugs or alcohol in the days preceding the experiments. Subjects were fully informed of the nature of the research and signed an informed consent before starting the experiment. Subjects were asked to sit comfortably in a reclining chair by keeping their arm fully relaxed in a natural position, with their hands resting on a pillow. The study was approved by the local ethical committee.

TMS. TMS was delivered through a MagStim monophasic Bistim 200 stimulator with a maximum output of $\sim 2.2$ tesla connected to a standard figure-of-eight $70 \mathrm{~mm}$ coil. To localize the "hotspot" of the leftdominant primary motor cortex (M1), the coil was held tangential to the scalp, with the handle pointing backward and laterally, angled at $45^{\circ}$ from the midline sagittal axis of the participant's head. Once the hotspot [i.e., the scalp point eliciting motor evoked potentials (MEPs) at threshold from the contralateral examined hand muscles] was found (Rossi et al., 2009), it was marked with a pencil to facilitate the application of the tACS target electrode.

tACS. tACS was delivered by a battery-driven current stimulator (NeuroConn) through surface saline-soaked sponge electrodes (size, $5 \times$ $7 \mathrm{~cm}$ ). Among the several possible electrode montages, we decided to use the same montage of a previous study (Feurra et al., 2011b), which proved frequency-and region-specific tACS effects. We reasoned that the same montage would be the best approach to confirm previous results with subjects at rest, as well as to investigate and compare corticospinal excitability changes induced by the MI task.

The center of the target electrode was placed over the left M1 hotspot, as determined by the TMS procedure. An additional electrode was used as reference and placed over the Pz position of the International 10-20 EEG System. Another target electrode was used as the control site to check for regional specificity of tACS effect and placed over P4, corresponding to the right PC (Fig. 1). The right PC seemed to be an optimal control region for the MI task, because it is involved in motor planning through ipsilateral and contralateral parietomotor connections (Koch et al., 2009). Rubber strips around the head guaranteed stable electrodescalp contacts for the three electrodes.

tACS was delivered at an intensity of $1000 \mu \mathrm{A}$ (500 $\mu \mathrm{A}$ peak-to-peak). The maximum current density at the stimulation electrode corresponded to $14.2 \mu \mathrm{A} / \mathrm{cm}^{2}$. The waveform of the stimulation was sinusoidal, and there was no direct current offset. The low intensity of stimulation was used to avoid a perception of flickering lights (Paulus, 2010), usually reported with higher stimulation intensities (Kanai et al., 2008). To minimize skin sensations, impedances were kept $<10 \mathrm{k} \Omega$.

TMS/tACS combined setting. Single pulses of TMS were delivered over the sponge electrode overlying the left M1 during ongoing tACS to index corticospinal excitability (Fig. 1). MEPs were recorded through $\mathrm{Ag}-\mathrm{AgCl}$ adhesive electrodes placed on the right first dorsal interosseus muscle, which is the prime mover of the pinch-grip action requested for the MI task (Feurra et al., 2011a; Bianco et al., 2012). Recordings started at least $20 \mathrm{~s}$ after the beginning of tACS delivery. The TMS intensity was adjusted to produce an MEP amplitude of $600-800 \mu \mathrm{V}$ (ranging $\sim 110-120 \%$ of the individual resting motor threshold) in baseline conditions (i.e., without tACS but still applied over the sponge electrode overlying the left M1). Ten MEPs per condition, spaced at least $7 \mathrm{~s}$, were recorded by a four-channel electromyograph (Phasis; EBNeuro), with a bandpass filter of $20 \mathrm{~Hz}$ to $5 \mathrm{kHz}$, sampled at $20 \mathrm{kHz}$, with a gain range of $0.1-1 \mathrm{mV}$. MEPs were discarded from post-processing if an EMG burst preceded the TMS by 300 to $0 \mathrm{~ms}$ or if there was an MEP-to-MEP onset latency jitter of $>2 \mathrm{~ms}$. This jitter accompanies any subliminal muscular activation, which in turn may bias the MEP amplitude (Rossi et al., 2008).

Each session of stimulation lasted no more than $90 \mathrm{~s}$ (Fig. 1a). The low intensity of tACS ensured that subjects did not feel any scalp sensation and that they were blind to each frequency of stimulation. The experimenters performing the offline MEP analysis were also blind to the type of tACS applied.

Throughout the experiment, a navigated stimulation system (SofTaxic optically tracked by EMS) was used (Fig. 1) to allow the exact repositioning of the TMS coil within and across experimental sessions. The navigation procedure, which minimizes the variability of TMS-induced electric fields directly measured within a scalp model, is fully described in a previous study (Feurra et al., 2011b).

Task. As detailed in Figure 1, 14 conditions were run: for both the MI and the resting condition, "Baseline 1," tACS on the left motor cortex at $5 \mathrm{~Hz}$ ( $\theta$ band), $10 \mathrm{~Hz}$ ( $\alpha$ band), $20 \mathrm{~Hz}$ ( $\beta$ band), $40 \mathrm{~Hz}$ ( $\gamma$ band), tACS on the right $\mathrm{PC}$ at $20 \mathrm{~Hz}$, and "Baseline 2." Baseline sessions did not involve tACS stimulation. In a previous study (Feurra et al., 2011b), the two baseline sessions were run separately (one at the beginning and one at the end of the task) to check for the stability of nonconditioned MEPs and for possible aftereffects of tACS conditioning. Here, we decided to fully randomize all conditions to vary the temporal window between the two baseline sessions.

For the MI task, subjects were requested to visually imagine a thumbindex finger pinch grip with their right hand (Bianco et al., 2012). Before starting the experiment, 10 min of practice were run to familiarize subjects with the task and with the brain stimulation procedures. Each TMS pulse was delivered 1-2 s after the initiation of the MI task, which followed a verbal "go" command (Rossini et al., 1999; Feurra et al., 2011a). At the end of the experiment, subjects reported to be unaware of whether tACS was applied on M1 or the PC. None of the subjects reported any scalp sensation or flickering sensations in their peripheral visual field.

Data analyses. After the exclusion of MEPs containing artifacts or muscular activity (as described above), the dataset comprised a mean \pm SD of $8.3 \pm 0.8$ MEPs for each cell of the experimental design: 18 subjects $\times 7$ tACS levels (Baseline 1, $\theta, \alpha, \beta, \gamma, 20 \mathrm{~Hz}$ PC, Baseline 2) $\times 2$ conditions (with and without MI). To model the dispersion among replications and use all the available information, we did not collapse the eight replications into an average value (such as mean or median). Accordingly, data analysis was performed by means of generalized estimating equations model (Hanley et al., 2003), with "subjects" as cluster variable and "tACS" and "condition" as within-subjects factors. Even if TMS pulses were spaced at least $7 \mathrm{~s}$ to avoid serial dependency, we chose an autoregressive-lag1 $[\mathrm{AR}(1)]$ working correlation to take into account potential residual autocorrelation. However, to test the robustness of our finding, $A R(1)$, the M-dependent working correlation was used, thus extending the window of the autocorrelation up to $M$ (we limited such a value to 4). Because MEP data followed a log-normal distribution, they could be made Gaussian by means of log transformation. This procedure reduced the frequency and the weight of outliers and improved variance homogeneity across experimental conditions. To assess the significance of experimental factors, the Wald test was used (the default option in SPSS GENLIN procedure). However, no difference was found when the Score test (based on Lagrange multiplier) was applied. In addition, the Sidak's multiple comparisons approach was chosen as an alternative to the Bonferroni's test, to slightly increase statistical power. 


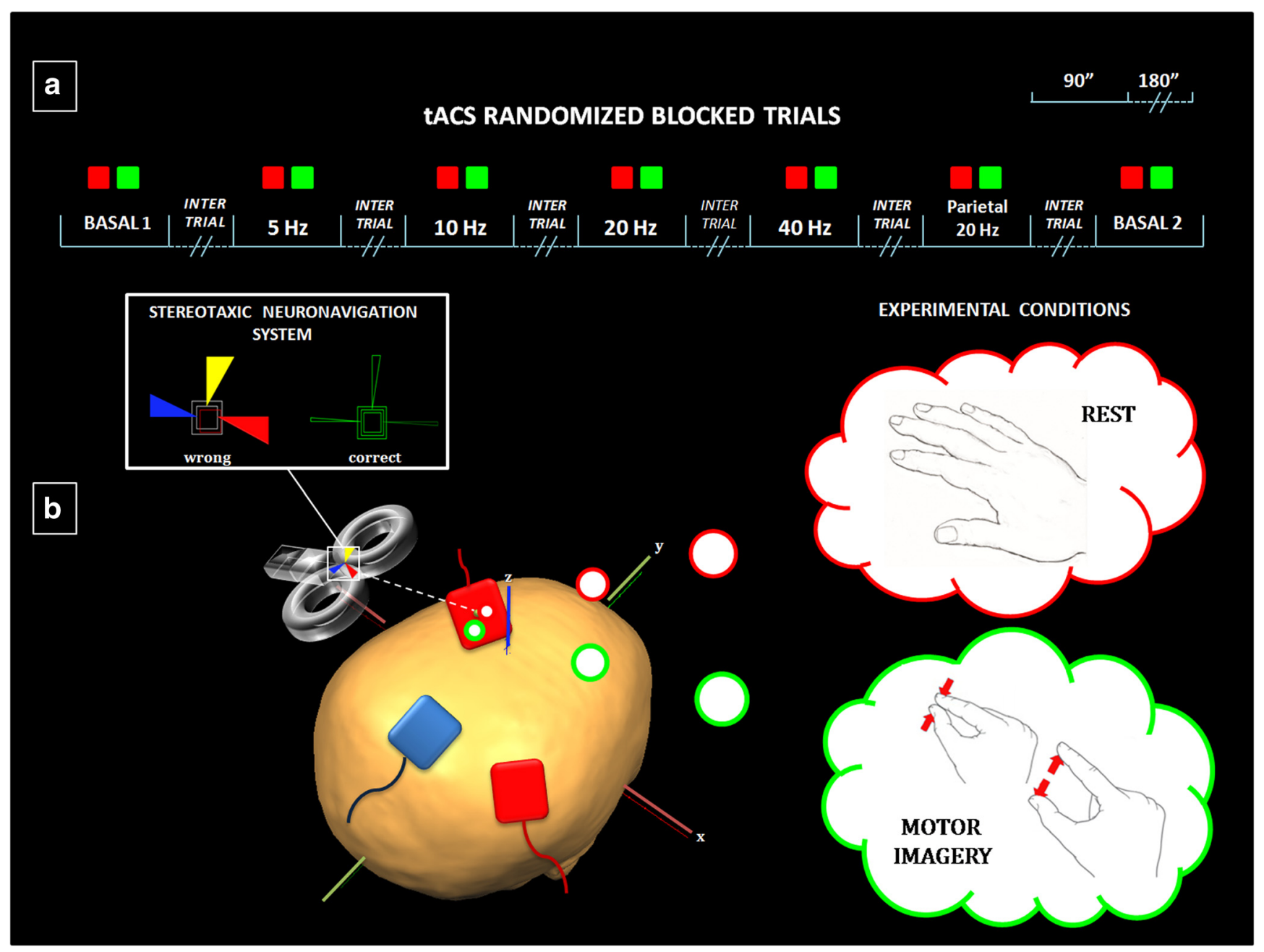

Figure 1. $\boldsymbol{a}$, Experimental design, with the 14 pseudorandom conditions during rest (red) and MI (green) of a pinch-grip action. $\boldsymbol{b}$, Red ("target") electrodes are placed on the scalp overlying the left motor cortex and the right PC (P4 position of the International 10 -20 EEG System). The blue ("reference") electrode is placed on the midline corresponding to the Pz position of the International $10-20$ EEG System. The coil for TMS is positioned over the "active" electrode on the motor cortex. The stereotaxic navigation system allowed to keep constant the coil positioning throughout the experiment, by using a three-dimensional online feedback.

\section{Results}

The main effect of condition was significant (Wald $=99.470 ; p<$ 0.001 ), confirming that MI robustly facilitates the corticospinal system: after a backtransformation to the original microvolt scale, MI increased MEPs from an average of $1076 \mu \mathrm{V}(95 \% \mathrm{CI}=$ $950-1219)$ to $2584 \mu \mathrm{V}(95 \% \mathrm{CI}=2172-3074)$. The main effect of tACS was not significant (Wald $=8.270 ; p=0.219$ ), whereas the interaction condition $\times$ tACS was highly significant $($ Wald $=$ 66.083; $p<0.001$ ). This indicated that tACS applied at different frequencies selectively affected the reactivity of the corticospinal system in the resting and MI conditions. First, we collapsed the two baseline conditions as they did not differ across MI and resting (Sidak's test, $p=1.0$ consistently). To better understand the interactive term, we contrasted each tACS stimulation level to the rest, and we observed the following: (1) the MEP increase during $\beta$-tACS without MI was significantly greater than the corresponding slight decrease during MI ( $p=0.004$; Fig. $2 b)$; (2) the MEP increase during $\theta$-tACS on MI was significantly greater than the corresponding slight decrease without MI $(p=0.020$; Fig. $2 b)$. At a descriptive level, the net effect of $\theta$-tACS versus no-tACS during MI (MEP increase: mean of $+40.1 \%$; $95 \% \mathrm{CI}=+5.4 \%$; $+86.3 \%$ ) was very similar to the net effect of $\beta$-tACS versus no-
tACS without MI (MEP increase: mean of $+39.8 \%$; $95 \%$ CI $=$ $+11.5 \%$; $+75.2 \%)$

Figure 2 and post hoc analysis corroborated these findings. When subjects were in a quiescent state, tACS at the $\beta$ range increased MEP size compared with the other conditions (vs rest, $p=0.023 ; \theta$-tACS, $p=0.010 ; \alpha$-tACS, $p=0.009 ; \gamma$-tACS, $p=$ 0.001 ; PC, $p=0.146$ ). During MI, $\beta$-tACS decreased MEP size (vs $\alpha$-tACS and $\theta$-tACS, $p=0.034$ and $p=0.001$, respectively) or had no effect (vs rest, $p=0.309 ; \gamma$-tACS, $p=0.782$; PC, $p=$ 0.988 ). MEP size during MI was instead increased with $\theta$-tACS compared with each other level (vs rest, $p=0.004$; $\beta$-tACS, $p=$ $0.001 ; \gamma$-tACS, $p=0.005$; PC, $p=0.001)$, except for $\alpha$-tACS $(p=$ 0.342 ), whereas $\theta$-tACS without MI had no effect (vs PC, $\gamma$-tACS, $\alpha$-tACS, rest, p values $>0.122$ ) or decreased MEP size (vs $\beta$-tACS, $p=0.019) . \alpha$-tACS also increased MEP size versus each other level during MI (vs rest, $p=0.029 ; \theta$-tACS, $p=0.342 ; \beta$-tACS, $p=0.034 ; \gamma$-tACS, $p=0.023$; PC, $p=0.021)$, whereas it had no effect (all $p$ values $>0.050$ ) without MI.

\section{Discussion}

Similar to single-pulse TMS delivered on different neocortical regions (Romei et al., 2008; Silvanto and Pascual-Leone, 2008), 


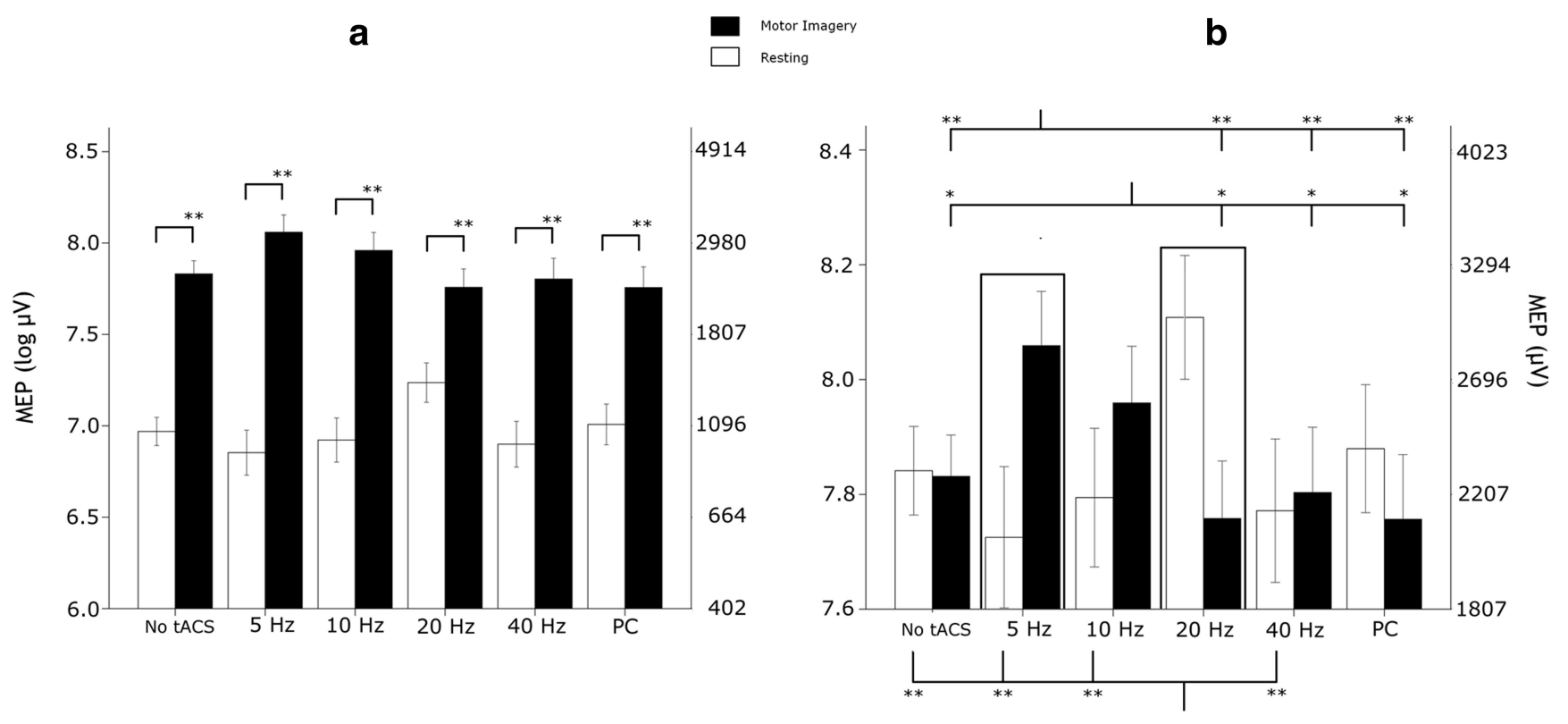

Figure 2. Changes of corticospinal reactivity (indexed by MEP size) in response to ongoing tACS at different frequencies, during rest (white bars) or MI (black bars). Error bars represent SEM. ${ }^{*} p<$ $0.05,{ }^{* *} p<0.01$. a represents the effects of both MEP modulating factors (stimulation and MI). Note the consistent increase of MEP size during MI versus the quiescence state, regardless of the type of tACS applied (MI vs resting for no-tACS, $\theta$-tACS, $\alpha$-tACS, $\gamma$-tACS, PC, $p<0.001$; and for $\beta$-tACS, $p=0.002$ ). $\boldsymbol{b}$ represents a zoom-in into the effects of the different tACS frequencies, after removing the average facilitatory main effect of $\mathrm{MI}$ [amplitude values are expressed both as $\log$ (left $y$-axis) and raw microvolt scale (left $y$-axis)]. Note the dissociation between conditions of $\theta$-tACS $(5 \mathrm{~Hz})$ and $\beta$-tACS $(20 \mathrm{~Hz})$ (see bar graph within the 2 rectangles), which highlights the state dependency of tACS effects: the corticospinal facilitation induced by MI, which was maximal during $\theta$-tACS, was lost during $\beta$-tACS; a reversal pattern was observed when subjects were at rest.

brain responses to an external rhythmic perturbation (either repetitive TMS or tACS) are strongly dependent on two main factors: (1) the frequency of stimulation (Kanai et al., 2008; Romei et al., 2010, 2011; Polanía et al., 2012); and (2) the momentary oscillatory phase (or initial state) of the underlying cortical activity (Thut et al., 2011). The neural signatures of this state dependency are frequency- and site-specific patterns of oscillatory activity that are phase-locked with the external stimulation and amplify preexisting natural brain oscillations in the stimulated neural network (Thut and Miniussi, 2009). This is the physiological substrate of the entrainment phenomenon (Ozen et al., 2010). By entraining ongoing brain oscillations, TMS and tACS may exert positive consequences on behavioral performance and therefore be used in rehabilitative settings of motor and cognitive functions (Rossi and Rossini, 2004). Recent evidence based on the simulation of large-scale networks of spiking neurons support the hypothesis that tACS exerts its action through the induction of frequency-specific network resonance (Ali et al., 2013).

In the current study, we assessed the level of corticospinal excitability of the stimulated motor cortex by measuring changes of MEPs size during rhythmic tACS application at different frequencies, as well as during different initial states of brain activity. MEP size reflects the magnitude of the output volley evoked by a fixed test stimulus applied on the cortex (Groppa et al., 2012).

\section{Confirmation of $\boldsymbol{\beta}$-tACS effects on the corticospinal system}

We confirmed that $\beta$-tACS on the motor cortex produced the maximal increase of corticospinal excitability while subjects were in a quiescent state (Feurra et al., 2011b). This effect was frequency dependent because it occurred only when the frequency of tACS $(20 \mathrm{~Hz})$ overlapped with the prevailing natural frequency (i.e., $\beta$ range) of motor areas at rest, supporting the notion that these oscillations have a functional relevance in tuning the level of corticospinal excitability (Gilbertson et al., 2005; Omlor et al.,
2011). Additionally, this effect was regionally specific, because $\beta$-tACS applied on the contralateral PC was not effective, despite ipsilateral and contralateral parietomotor connections (Koch et al., 2009).

\section{Novel results: state dependency of tACS effects}

MI, which changes the frequency of the natural oscillatory activity of the sensorimotor network (McFarland et al., 2000; Pfurtscheller, 2000; Salenius and Hari, 2003), induced several main effects. The first main effect was a robust corticospinal facilitation toward the muscles engaged in the MI task, regardless of experimental conditions (Fig. 2a). This was an expected, solid result in line with a number of previous studies (Fadiga et al., 1999; Rossini et al., 1999; Munzert et al., 2009; Bianco et al., 2012). The second effect was a reduction of the corticospinal reactivity to $\beta$-tACS, which was no longer effective in increasing the level of local excitability (Fig. 2b). The third effect was a maximal frequency-dependent and region-specific enhancement of corticospinal excitability when the TMS test pulse coincided with tACS at $\theta$ range $(5 \mathrm{~Hz})$ on the motor cortex but not on the PC (Fig. 2). This finding further supports the notion of frequency dependence and regional specificity of tACS effects on the motor system and shows a definite state dependency of these effects, which is a novel evidence for the motor domain. This fits with the notion that resonance phenomena between externally applied and internally generated rhythms are state dependent, that is, they are determined by a dynamic interplay between task demands (Varela et al., 2001) and the initial state of the underlying neural activity (Thut et al., 2011).

\section{Entrainment or phase cancellation?}

State dependency of tACS effects in the motor system was expected on the basis of previous data in the visual domain (Kanai et al., 2008) but not yet tested nor neurophysiologically demon- 
strated. There are at least two possible ways by which frequencytuned rhythmic protocols can lead to frequency-specific effects: the former is entrainment of ongoing oscillations leading to synchronization (Thut et al., 2011), and the latter is phase cancellation of ongoing oscillations leading to desynchronization (Brittain et al., 2013). According to the little currently available evidence (Polanía et al., 2012, Brittain et al., 2013), phase cancellation has only been obtained either after long periods of tACS ( $~ 14$ min in the study by Polanía et al., 2012; $\sim 10 \mathrm{~min}$ in the study by Brittain et al., 2013) or with high intensity of stimulation ( $2 \mathrm{~mA}$ in the study by Brittain et al., 2013). Brittain et al. (2013) also showed that a partial suppression of peripheral tremor in parkinsonian patients, possibly occurring through adaptation of the dysfunctional motor system, could be obtained only after a sustained period of phase cancellation. Therefore, it seems unlikely that the stimulation parameters that we used ( $90 \mathrm{~s}$ at $1 \mathrm{~mA}$ ) induced such a robust adaptation of the corticospinal system excitability. This experimental timing better fits the entrainment hypothesis, because the time lag between a rhythmic perturbation of the ongoing oscillatory activity and entrainment occurrence is instantaneous (Thut et al., 2011; Ali et al., 2013).

\section{Effects of the $\theta$-tACS}

The possible entrainment during $\mathrm{MI}$ in the $\theta$ range rather than in the $\beta$ range (Feurra et al., 2011b) might reflect the increased load of WM processes required to mentally maintain and execute the task throughout the experiment. WM processes are associated with slow $\theta$ oscillations in a wide frontoparietal network underlying visuospatial memory and visuomotor functions (Düzel et al., 2010; Sauseng et al., 2010), which play a key role in encoding multiple items in a defined order or spatial arrangement (Lisman and Buzsáki, 2008). Slow frequency oscillations (4-12 Hz) subserve long-distance interactions such as those occurring in the frontoparietal WM network, whereas high-frequency oscillations $(20-100 \mathrm{~Hz})$ are engaged in local interactions within the same brain region (von Stein and Sarnthein, 2000; Ward, 2003).

The question arises as to why endogenous frontoparietal $\theta$ oscillations, commonly associated with visuospatial WM processes, would facilitate corticospinal output during MI, and $\theta$-tACS would further increase it. Emerging evidence suggests a role of task-related $\theta$ synchronization in the motor system, associated with sensorimotor integration (Cruikshank et al., 2012) and improvement of motor performance during preparation to intercept and catch a moving object (Tombini et al., 2009; Rawle et al., 2012), reaching and pointing movements (Perfetti et al., 2011), and imagery of movements for learning (Kaplan et al., 2012). Altogether, these results indicate that the corticospinal system-through the M1 as an executor-may play a role in the finalization of the converging inputs from the widely distributed frontoparietal network engaged in visuomotor WM. One hypothesis is that tACS at the $\theta$ range amplifies endogenous $\theta$ oscillations, thereby inducing a facilitation of the corticospinal system during MI. With the adopted montage (motor cortex-vertex), an increase of the regional $\theta$ parietal activity may have facilitated phase-coupling in the parietofrontal networks (Polanía et al., 2012). Crucially, the integrity of this structural network is decisive for successful post-stroke modulation of sensorimotor rhythms based on MI training (Buch et al., 2012).

\section{Effects of the $\alpha$-tACS}

During MI, $\alpha$-tACS also increased the corticospinal output versus other tACS frequencies, although to a lesser extent than $\theta$-tACS (Fig. 2b). At first glance, this finding does not reconcile with the notion that the mu rhythm (usually in the $\alpha$ range) desynchronizes with MI or movement preparation (Pfurtscheller, 2000). Moreover, this effect seems to be in contrast with the resonance hypothesis (Feurra et al., 2011b). One possible explanation is that subjects were engaged in a visual rather than kinesthetic MI task. Although kinesthetic MI is linked with a clear contralateral event-related desynchronization of $\alpha$-and $\beta$-frequency bands, visual MI is linked to synchronization of these oscillatory patterns (Neuper et al., 2005). Moreover, an increase of $\alpha$ activity is associated with visual attention (Sauseng et al., 2005), WM load (Sauseng et al., 2009), and motor planning (Sabate et al., 2012), three processes that may contribute to successful MI. Together, these nonmutually exclusive factors may contribute to an increase of locoregional $\alpha$ rhythms, making them more likely to be entrained by tACS at $10 \mathrm{~Hz}$, as suggested by the resonance hypothesis. In this vein, the increase of corticospinal output during $\alpha$-tACS combined with MI may indicate that the $\alpha$ rhythm, which is known to reflect the degree of cortical inhibition (Klimesch et al., 2007), may instead contribute to increase the corticospinal excitability of the motor system, again in a state-dependent manner. Similarly, rhythmic TMS tuned at individual $\alpha$ band triggers natural brain oscillations in the same frequency range (Thut et al., 2011) and improves task performance when concurrently applied during a mental rotation tasks (Klimesch et al., 2003).

\section{Effects of the $\gamma$-tACS}

We did not observe changes of corticospinal excitability during $\gamma$-tACS, at variance with the notion that oscillations in $\gamma$ band play a key role during voluntary movement (Ball et al., 2008; Joundi et al., 2012; Pollok et al., 2012). In those studies, the range of $\gamma$-band oscillations accompanying actual movements ranged from 50 to $90 \mathrm{~Hz}$ (mid-high $\gamma$ ), well beyond the $\gamma$-tACS range we applied ( $40 \mathrm{~Hz}$, low $\gamma$ band). In addition, the experiment involved MI rather than actual movements. Thus, according to the entrainment theory, the applied frequency would not have been able to amplify such a different endogenous rhythm. Instead, the role of theta synchronization during MI is well known (Tombini et al., 2009; Kaplan et al., 2012; Rawle et al., 2012) and is in line with both the results of this study and the interpretation about a possible entrainment of $\theta$-tACS effects, rather than phase cancellation, during MI.

\section{Conclusions}

The current study provides novel evidence that tACS effects in the motor system are state dependent besides being frequency dependent and regional specific and that this state dependency can be indexed by a neurophysiological measure of corticospinal output. More work and technological advances (Soekadar et al., 2013) are needed to directly demonstrate that theta-tACS increases not only the motor output but also scalp-recorded EEG power in the theta range, which would provide a neural signature of resonance phenomena between externally applied and internally generated oscillations.

\section{References}

Ali MM, Sellers KK, Fröhlich F (2013) Transcranial alternating current stimulation modulates large-scale cortical network activity by network resonance. J Neurosci 33:11262-11275. CrossRef Medline

Ball T, Demandt E, Mutschler I, Neitzel E, Mehring C, Vogt K, Aertsen A, Schulze-Bonhage A (2008) Movement related activity in the high gamma range of the human EEG. Neuroimage 41:302-310. CrossRef Medline

Bianco G, Feurra M, Fadiga L, Rossi A, Rossi S (2012) Bi-hemispheric effects on corticospinal excitability induced by repeated sessions of imagery ver- 
sus observation of actions. Restor Neurol Neurosci 30:481-489. CrossRef Medline

Brittain JS, Probert-Smith P, Aziz TZ, Brown P (2013) Tremor suppression by rhythmic transcranial current stimulation. Curr Biol 23:436-440. CrossRef Medline

Buch ER, Modir Shanechi A, Fourkas AD, Weber C, Birbaumer N, Cohen LG (2012) Parietofrontal integrity determines neural modulation associated with grasping imagery after stroke. Brain 135:596-614. CrossRef Medline

Cruikshank LC, Singhal A, Hueppelsheuser M, Caplan JB (2012) Theta oscillations reflect a putative neural mechanism for human sensorimotor integration. J Neurophysiol 107:65-77. CrossRef Medline

Decety J, Grèzes J (1999) Neural mechanisms subserving the perception of human actions. Trends Cogn Sci 3:172-178. CrossRef Medline

Düzel E, Penny WD, Burgess N (2010) Brain oscillations and memory. Curr Opin Neurobiol 20:143-149. CrossRef Medline

Fadiga L, Buccino G, Craighero L, Fogassi L, Gallese V, Pavesi G (1999) Corticospinal excitability is specifically modulated by motor imagery: a magnetic stimulation study. Neuropsychologia 37:147-158. CrossRef Medline

Feurra M, Bianco G, Polizzotto NR, Innocenti I, Rossi A, Rossi S (2011a) Cortico-cortical connectivity between right parietal and bilateral primary motor cortices during imagined and observed actions: a combined TMS/ tDCS Study. Front Neural Circuits 5:10. CrossRef Medline

Feurra M, Bianco G, Santarnecchi E, Del Testa M, Rossi A, Rossi S (2011b) Frequency-dependent tuning of the human motor system induced by transcranial oscillatory potentials. J Neurosci 31:12165-12170. CrossRef Medline

Feurra M, Paulus W, Walsh V, Kanai R (2011c) Frequency specific modulation of human somatosensory cortex. Front Psychol 2:13. CrossRef Medline

Feurra M, Galli G, Rossi S (2012) Transcranial alternating current stimulation affects decision making. Front Syst Neurosci 6:39. CrossRef Medline

Gilbertson T, Lalo E, Doyle L, Di Lazzaro V, Cioni B, Brown P (2005) Existing motor state is favored at the expense of new movement during $13-35 \mathrm{~Hz}$ oscillatory synchrony in the human corticospinal system. J Neurosci 25:7771-7779. CrossRef Medline

Groppa S, Oliviero A, Eisen A, Quartarone A, Cohen LG, Mall V, Kaelin-Lang A, Mima T, Rossi S, Thickbroom GW, Rossini PM, Ziemann U, Valls-Solé J, Siebner HR (2012) A practical guide to diagnostic transcranial magnetic stimulation: report of an IFCN committee. Clin Neurophysiol 123: 858-882. CrossRef Medline

Hanley JA, Negassa A, Edwardes MD, Forrester JE (2003) Statistical analysis of correlated data using generalized estimating equations: an orientation. Am J Epidemiol 157:364-375. CrossRef Medline

Jeannerod M (1995) Mental imagery in the motor context. Neuropsychologia 33:1419-1432. CrossRef Medline

Joundi RA, Jenkinson N, Brittain JS, Aziz TZ, Brown P (2012) Driving oscillatory activity in the human cortex enhances motor performance. Curr Biol 22:403-407. CrossRef Medline

Kanai R, Chaieb L, Antal A, Walsh V, Paulus W (2008) Frequencydependent electrical stimulation of the visual cortex. Curr Biol 18:18391843. CrossRef Medline

Kanai R, Paulus W, Walsh V (2010) Transcranial alternating current stimulation (tACS) modulates cortical excitability as assessed by TMSinduced phosphene thresholds. Clin Neurophysiol 121:1551-1554. CrossRef Medline

Kaplan R, Doeller CF, Barnes GR, Litvak V, Düzel E, Bandettini PA, Burgess N (2012) Movement-related theta rhythm in humans: coordinating self-directed hippocampal learning. PLoS Biol 10:e1001267. CrossRef Medline

Klimesch W, Sauseng P, GerloffC (2003) Enhancing cognitive performance with repetitive transcranial magnetic stimulation at human individual alpha frequency. Eur J Neurosci 17:1129-1133. CrossRef Medline

Klimesch W, Sauseng P, Hanslmayr S (2007) EEG alpha oscillations: the inhibition-timing hypothesis. Brain Res Rev 53:63-88. CrossRef Medline

Koch G, Ruge D, Cheeran B, Fernandez Del Olmo M, Pecchioli C, Marconi B, Versace V, Lo Gerfo E, Torriero S, Oliveri M, Caltagirone C, Rothwell JC (2009) TMS activation of interhemispheric pathways between the posterior parietal cortex and the contralateral motor cortex. J Physiol 587: 4281-4292. CrossRef Medline

Lisman J, Buzsáki G (2008) A neural coding scheme formed by the com- bined function of gamma and theta oscillations. Schizophr Bull 34:974980. CrossRef Medline

Marshall L, Helgadóttir H, Mölle M, Born J (2006) Boosting slow oscillations during sleep potentiates memory. Nature 444:610-613. CrossRef Medline

McFarland DJ, Miner LA, Vaughan TM, Wolpaw JR (2000) Mu and beta rhythm topographies during motor imagery and actual movements. Brain Topogr 12:177-186. CrossRef Medline

Munzert J, Lorey B, Zentgraf K (2009) Cognitive motor processes: the role of motor imagery in the study of motor representations. Brain Res Rev 60:306-326. CrossRef Medline

Neuper C, Scherer R, Reiner M, Pfurtscheller G (2005) Imagery of motor actions: differential effects of kinesthetic and visual-motor mode of imagery in single-trial EEG. Brain Res Cogn Brain Res 25:668-677. CrossRef Medline

Niedermeyer E (1999) The normal EEG of the waking adult. In: Electroencephalography: basic principles, clinical applications, and related fields (Niedermeyer E, Lopes da Silva F, eds), pp 149-173. Baltimore: Lippincott Williams and Wilkins.

Omlor W, Patino L, Mendez-Balbuena I, Schulte-Mönting J, Kristeva R (2011) Corticospinal beta-range coherence is highly dependent on the pre-stationary motor state. J Neurosci 31:8037-8045. CrossRef Medline

Ozen S, Sirota A, Belluscio MA, Anastassiou CA, Stark E, Koch C, Buzsáki G (2010) Transcranial electric stimulation entrains cortical neuronal populations in rats. J Neurosci 30:11476-11485. CrossRef Medline

Paulus W (2010) On the difficulties of separating retinal from cortical origins of phosphenes when using transcranial alternating current stimulation (tACS). Clin Neurophysiol 121:987-991. CrossRef Medline

Perfetti B, Moisello C, Landsness EC, Kvint S, Lanzafame S, Onofrj M, Di Rocco A, Tononi G, Ghilardi MF (2011) Modulation of gamma and theta spectral amplitude and phase synchronization is associated with the development of visuo-motor learning. J Neurosci 31:14810-14819. CrossRef Medline

Pfurtscheller G (2000) Spatiotemporal ERD/ERS patterns during voluntary movement and motor imagery. Suppl Clin Neurophysiol 53:196-198. CrossRef Medline

Pogosyan A, Gaynor LD, Eusebio A, Brown P (2009) Boosting cortical activity at beta-band frequencies slows movement in humans. Curr Biol 19:1637-1641. CrossRef Medline

Polanía R, Nitsche MA, Korman C, Batsikadze G, Paulus W (2012) The importance of timing in segregated theta phase-coupling for cognitive performance. Curr Biol 22:1314-1318. CrossRef Medline

Pollok B, Krause V, Martsch W, Wach C, Schnitzler A, Sudmeyer M (2012) Motor-cortical oscillations in early stages of Parkinson's disease. J. Physiol 590:3203-3212. CrossRef Medline

Rawle CJ, Miall RC, Praamstra P (2012) Frontoparietal theta activity supports behavioral decisions in movement-target selection. Front Hum Neurosci 6:138. CrossRef Medline

Romei V, Brodbeck V, Michel C, Amedi A, Pascual-Leone A, Thut G (2008) Spontaneous fluctuations in posterior alpha band EEG activity reflect variability in excitability of human visual area. Cereb Cortex 18:20102018. CrossRef Medline

Romei V, Gross J, Thut G (2010) On the role of prestimulus alpha rhythms over occipito-parietal areas in visual input regulation: correlation or causation? J Neurosci 30:8692-8697. CrossRef Medline

Romei V, Driver J, Schyns PG, Thut G (2011) Rhythmic TMS over parietal cortex links distinct brain frequencies to global versus local visual processing. Curr Biol 21:334-337. CrossRef Medline

Rosanova M, Casali A, Bellina V, Resta F, Mariotti M, Massimini M (2009) Natural frequencies of human corticothalamic circuits. J Neurosci 29: 7679-7685. CrossRef Medline

Rossi S, Rossini PM (2004) TMS in cognitive plasticity and the potential for rehabilitation. Trends Cogn Sci 8:273-279. CrossRef Medline

Rossi S, De Capua A, Pasqualetti P, Ulivelli M, Fadiga L, Falzarano V, Bartalini S, Passero S, Nuti D, Rossini PM (2008) Distinct olfactory cross-modal effects on the human motor system. PLoS One 3:e1702. CrossRef Medline

Rossi S, Hallett M, Rossini PM, Pascual-Leone A (2009) Safety, ethical considerations, and application guidelines for the use of transcranial magnetic stimulation in clinical practice and research. Clin Neurophysiol 120:2008-2039. CrossRef Medline

Rossini PM, Rossi S, Pasqualetti P, Tecchio F (1999) Corticospinal excitabil- 
ity modulation to hand muscles during movement imagery. Cereb Cortex 9:161-167. CrossRef Medline

Sabate M, Llanos C, Enriquez E, Rodriguez M (2012) Mu rhythm, visual processing and motor control. Clin Neurophysiol 123:550-557. CrossRef Medline

Salenius S, Hari R (2003) Synchronous cortical oscillatory activity during motor action. Curr Opin Neurobiol 13:678-684. CrossRef Medline

Santarnecchi E, Polizzotto NR, Godone M, Giovannelli F, Feurra M, Matzen L, Rossi A, Rossi S (2013) Frequency-dependent enhancement of fluid intelligence induced by transcranial oscillatory potentials. Curr Biol 23: 1449-1453. CrossRef Medline

Sauseng P, Klimesch W, Stadler W, Schabus M, Doppelmayr M, Hanslmayr S, Gruber WR, Birbaumer N (2005) A shift of visual spatial attention is selectively associated with human EEG alpha activity. Eur J Neurosci 22:2917-2926. CrossRef Medline

Sauseng P, Klimesch W, Heise KF, Gruber WR, Holz E, Karim AA, Glennon M, Gerloff C, Birbaumer N, Hummel FC (2009) Brain oscillatory substrates of visual short-term memory capacity. Curr Biol 19:1846-1852. CrossRef Medline

Sauseng P, Griesmayr B, Freunberger R, Klimesch W (2010) Control mechanisms in working memory: a possible function of EEG theta oscillations. Neurosci Biobehav Rev 34:1015-1022. CrossRef Medline

Sela T, Kilim A, Lavidor M (2012) Transcranial alternating current stimulation increases risk-taking behavior in the balloon analog risk task. Front Neurosci 6:22. CrossRef Medline
Silvanto J, Pascual-Leone A (2008) State-dependency of transcranial magnetic stimulation. Brain Topogr 21:1-10. CrossRef Medline

Soekadar SR, Witkowski M, Cossio EG, Birbaumer N, Robinson SE, Cohen LG (2013) In vivo assessment of human brain oscillations during application of transcranial electric currents. Nat Commun 4:2032. CrossRef

Thut G, Miniussi C (2009) New insights into rhythmic brain activity from TMS-EEG studies. Trends Cogn Sci 13:182-189. CrossRef Medline

Thut G, Veniero D, Romei V, Miniussi C, Schyns P, Gross J (2011) Rhythmic TMS causes local entrainment of natural oscillatory signatures. Curr Biol 21:1176-1185. CrossRef Medline

Tombini M, Zappasodi F, Zollo L, Pellegrino G, Cavallo G, Tecchio F, Guglielmelli E, Rossini PM (2009) Brain activity preceding a 2D manual catching task. Neuroimage 47:1735-1746. CrossRef Medline

Varela F, Lachaux JP, Rodriguez E, Martinerie J (2001) The brainweb: phase synchronization and large-scale integration. Nat Rev Neurosci 2:229_ 239. CrossRef Medline

von Stein A, Sarnthein J (2000) Different frequencies for different scales of cortical integration: from local gamma to long range alpha/theta synchronization. Int J Psychophysiol 38:301-313. CrossRef Medline

Ward LM (2003) Synchronous neural oscillations and cognitive processes. Trends Cogn Sci 7:553-559. CrossRef Medline

Zaehle T, Rach S, Herrmann CS (2010) Transcranial alternating current stimulation enhances individual alpha activity in human EEG. PLoS One 5:e13766. CrossRef Medline 